\title{
Initial Assessment of Acoustic Source Visibility with a 24-element Microphone Array in the Arnold Engineering Development Center 80- by 120-Foot Wind Tunnel at NASA Ames Research Center
}

\author{
William C. Horne ${ }^{*}$ \\ NASA Ames Research Center, Moffett Field, California 94035
}

\begin{abstract}
Measurements of background noise were recently obtained with a 24-element phased microphone array in the test section of the Arnold Engineering Development Center 80by120-Foot Wind Tunnel at speeds of 50 to $100 \mathrm{knots}(27.5$ to $51.4 \mathrm{~m} / \mathrm{s})$. The array was mounted in an aerodynamic fairing positioned with array center $1.2 \mathrm{~m}$ from the floor and 16 $\mathrm{m}$ from the tunnel centerline, The array plate was mounted flush with the fairing surface as well as recessed $1 / 2$ in. $(1.27 \mathrm{~cm})$ behind a porous Kevlar screen. Wind-off speaker measurements were also acquired every $15^{\circ}$ on a $10 \mathrm{~m}$ semicircular arc to assess directional resolution of the array with various processing algorithms, and to estimate minimum detectable source strengths for future wind tunnel aeroacoustic studies. The dominant background noise of the facility is from the six drive fans downstream of the test section and first set of turning vanes. Directional array response and processing methods such as background-noise cross-spectral-matrix subtraction suggest that sources 10-15 dB weaker than the background can be detected.
\end{abstract}

\section{Background}

Phased microphone arrays provide benefits of directional response and suppression of uncorrelated flow noise when used to measure sound from model sources in a variety of wind tunnel test environments, including open jets and closed test sections (hard-wall and treated). Fixed and traversing microphone arrays were used successfully in the NASA Ames 40-by 80-Foot Wind Tunnel (now managed by Air Force/Arnold Engineering Development Center) to measure airframe noise sources ${ }^{1}$, but have not been used previously in the $80 \times 120 \mathrm{ft}$ test section which operates from the same fan drive, as sketched in Fig. 1.

The 40-by 80-foot test section has a 42 inch $(1.07 \mathrm{~m})$ deep acoustic liner, acoustically treated turning vanes, and other modifications for low-noise operation to $300 \mathrm{kts}(154 \mathrm{~m} / \mathrm{s})$. The 80 -by 120 -foot test section has acoustic lining 6-inch $(0.12 \mathrm{~m})$ deep on the floor and ceiling, 10 inches thick on the walls, and operates to $100 \mathrm{kts}(51.4 \mathrm{~m} / \mathrm{s})$. It is much closer to the drive fans and the drive noise dominates the background noise of acoustic sensors in the larger test section. Since this test section is large enough for testing large- or full-scale models of rotorcraft, wind turbines, and powered aircraft, it is of interest to improve the quality of acoustic measurements by reducing the effects of background noise, and to determine acoustic source levels for which reliable measurements may be obtained.

Since the tunnels were last acoustically modified in the 1990's, significant technical progress has been achieved in array design and processing algorithms. Source levels considerably lower than measurable with conventional in-flow microphones can be resolved with arrays which can also indicate the location of prominent noise sources on the model $^{1}$.

\section{Instrumentation and Set-up}

A plan view of the Air Force/AEDC National Full-Scale Aerodynamics Complex (NFAC) in the 80- by 120- $\mathrm{ft}$ operating mode is shown in Fig. 1. In the 40x80 mode, acoustically treated turning vanes and 42-inch deep acoustic liner minimize fan drive noise in the test section. In the 80x120 mode, the test section with 6” deep liner is approximately $360 \mathrm{ft}(110 \mathrm{~m})$ upstream of the drive fans, separated by two untreated vane sets.

*Aerospace Engineer, Experimental Aerophysics Branch(AOX), Associate Fellow AIAA 
An assessment of measurability of acoustic sources in the 80-by 120 -foot test section was recently carried out for speeds up to $100 \mathrm{kts}(51.4 \mathrm{~m} / \mathrm{s})$ with a fixed 24-element, $15 \mathrm{in}$. diameter $(0.38 \mathrm{~m})$ array. The data was acquired in about 40 minutes of tunnel running at the end of a non-acoustic test. The array was mounted in a 42.5 in. $(1.08 \mathrm{~m})$ square plywood plate approximately $4 \mathrm{ft}(1.2 \mathrm{~m})$ from the tunnel floor and 9 $\mathrm{ft}(3 \mathrm{~m})$ from the left wall. The array plate was mounted in an aerodynamic fairing $80 \mathrm{in.} \mathrm{long,} 50$ in wide, and 4 in thick ( $2.03 \times 1.27 \times 0.101 \mathrm{~m})$ with the plate flush with the fairing surface (fig. 2, left), as well as recessed 0.5 inches $(1.27 \mathrm{~cm})$ behind a porous Kevlar screen (fig. 2, right). The fairing was tilted back about $15^{\circ}$ from vertical during the test. In previous test programs, the Kevlar screen has been found to reduce direct pressure fluctuations (by 5-10 dB at $120 \mathrm{kts}$ ) from the boundary layer over the fairing, but can introduce other acoustic effects such as reverberation of $+/-2 \mathrm{~dB}$ depending on frequency ${ }^{1}$.

The microphones in the array were Countryman B3 0.2" electret lavalier microphones with flat response (+/- $3 \mathrm{~dB}$ ) from 100 to 20,000 Hz. Three 8-channel PreSonus power supply/preamplifier modules powered the 24 microphones. A removable TMS 1/4" free-field condenser microphone was added to the array plate to permit pistonphone calibrations. The array was also provided with a webcam imager with USB port connection. The microphone data was digitized with a MOTU 24 I/O 24 ch, 24 bit simultaneous A/D at $48 \mathrm{ksamp} / \mathrm{sec}$ (96 ksamp/sec available). The array plate with microphones and imager, pre-amps, $\mathrm{A} / \mathrm{D}$, acquisition control computer, acquisition and processing software were procured as a unit from Optinav, Inc ${ }^{2}$.

In addition to the wind-on background noise measurements, wind-off speaker calibrations were performed to assess the spatial resolution of the array in various directions. These measurements will be described in the following sections.

\section{Results and Discussion}

\section{A. Spatial Resolution}

The predicted response of the array to a point source (point-spread-function) $20 \mathrm{ft}(6.1 \mathrm{~m})$ from array center is shown in figure 3 . for frequencies of $1,2.5,10$, and $15 \mathrm{kHz}$, using conventional delay-andsum beamforming. The processing software also provided iterative post-processing of the beamformed results to improve resolution and remove sidelobes, including the MUSIC, DAMAS 2, CLEAN-SC, and TIDY algorithms.

The broadside response and ability to discriminate between two adjacent sources can be approximated by the Rayleigh criterion: $\Delta \theta \sim 1.22 \lambda / \mathrm{D}$, where $\Delta \theta$ is the angular separation between sources in radians, $\lambda=$ acoustic wavelength, $\mathrm{D}=$ diameter of the circle enclosing the array microphones. The criterion estimates being able to separate sources $15^{\circ}$ apart at about $4 \mathrm{kHz}$. The resolution degrades roughly as $1 / \cos (\theta)$ for off-axis sources, where $\theta$ is the angle measured from the normal to the array plate.

The wind-off response of the array in the test section was measured with a Fender loudspeaker driven at 0.5 Watts with a pink-noise source between 0.1 and $20 \mathrm{kHz}$. The loudspeaker was positioned on a semicircle with $32.8 \mathrm{ft}(10 \mathrm{~m})$ radius at 15 degree increments between 0 and 180 degrees, as shown in Fig. 4. A wide range of off-axis source angles may be encountered during array traverses in which the array plate remains oriented with the stream- wise direction. Due to limited availability of test time for this assessment, wind-on speaker calibrations were not attempted, but instead simulated by adding the microphone time-histories of the wind-off speaker signals to the wind-on empty tunnel background noise, as discussed in the third results section. This method omits real flow effects such as convection and distortion of the source wavefronts through the fairing boundary layer, but will give an estimate of the minimum source strength detectable by the array using various processing algorithms. Comparisons between this method and actual wind-on speaker calibrations were preformed in a subsequent study ${ }^{2}$ in a 32 -in by 48 in subsonic tunnel ${ }^{3}$, and are also planned for the 40 - by 80 -ft wind tunnel in the near future.

Figure 5 shows composites of the array camera image and the beamformed results of the superposition of loudspeaker signals from the thirteen loudspeaker positions on the $10 \mathrm{~m}$ radius semicircle, 
at the $1 / 3$ octave band centered at 4 and $5 \mathrm{kHz}$ (left and right images, respectively) using the TIDY processing option.

The hemispherical scan option in the processing software developed source location information over the full hemisphere visible to the array plate. The radial plot dimension is scaled as $\cos (\theta)$, so that the source images retain a symmetrical appearance, although the off-axis degradation in resolution is apparent with the appearance of more sidelobes in the off -axis directions. The source propagation paths are close to the tunnel floor and the floor reflections due to grazing incidence (frequency dependent) are evident in the plots.

These results are consistent with Dougherty's assessment resolution of a broadside source pair using conventional beamforming, DAMAS2, TIDY, CLEAN-SC, and MUSIC algorithms ${ }^{4}$. In this assessment, conventional beamforming resolved broadside sources at the Rayleigh limit(RL), CLEAN-SC at $0.803 \mathrm{RL}$, DAMAS2 and TIDY at $0.638 \mathrm{RL}$, and MUSIC with the best broadside resolution at $0.405 \mathrm{RL}$

\section{B. Wind-on background noise}

Empty test-section background noise was acquired at 50, 60, 75, 90, and 100 kts (Mach 0.075, 0.09, 0.113, 0.135, 0.15, V = 25.7, 30.84, 38.55, 46.26, and $51.4 \mathrm{~m} / \mathrm{s}$ ). Data from 50, 75, and $100 \mathrm{kt}$ conditions are presented here. Data was acquired for 42 and 82 second consecutive records on one day with the array in the flush-plate configuration, and on the following day with the Kevlar screen installed.

Selected hemispherical array scans for the flush and Kevlar configurations at 1, 5, and $10 \mathrm{kHz}$ using TIDY processing to suppress sidelobes are shown for $\mathrm{M}=0.15$ in Fig. 6 . In the flush configuration, strong fan noise at $1 \mathrm{kHz}$ is seen at the right in Fig 6a, along with a sidelobe residue that extends across the middle of the image. At 5 and $10 \mathrm{kHz}$ (Fig. 6a and 6b), the dominant noise source (flush plate) is residual noise from the boundary layer appearing as random spots across the hemisphere. The flow direction is from left to right.

At $1 \mathrm{kHz}$, the Kevlar-treated array (Fig. 6d) the fan source and sidelobe pattern is similar to the corresponding image for the flush plate Fig. 6a), except for a $2 \mathrm{~dB}$ level difference. The random spots associated with array plate turbulence seen in the flush configuration are absent in the Kevlar-treated plate results at 5 and $10 \mathrm{kHz}$ (Fig. 6e and 6f), however an arc of sources towards the leading edge becomes the dominant noise source. This is likely due to boundary layer turbulence over the leading edge of the fairing scattering sound as it convects over the discontinuity between the porous Kevlar screen and the solid support plate that surrounds it. This source would be fairly easy to treat locally with damping material. Distributed "scrubbing noise" from turbulent flow over the Kevlar screen does not show up as a strong source, a concern from previous tests that did not scan the full hemisphere.

Third octave spectra of microphone 1 (near array center) and the peak conventional beamform level for the flush and Kevlar-treated configurations are shown in Fig. 7a, 7b, and 7c for 50, 75, and $100 \mathrm{kt}$ $(17.1,34.3$, and $51.4 \mathrm{~m} / \mathrm{s})$ respectively. The spectra are corrected by $-6.02 \mathrm{db}$ to remove the pressuredoubling effect of the array plate. Below $3 \mathrm{kHz}$, the beamform peak levels are similar despite large differences (up to $15 \mathrm{~dB}$ ) in the noise level of the individual microphone. Above $3 \mathrm{kHz}$, the flush plate response exceeds the Kevlar-treated plate by amounts that increase with tunnel speed, corresponding to the beamform artifacts associated with boundary layer turbulence over the flush plate. The Kevlar-treated beamform peak levels out with increasing frequency above $5 \mathrm{kHz}$, corresponding to the appearance of the scattering source at the leading edge of the porous screen.

\section{Estimates of source visibility}

Source detectabililty thresholds and level measurement accuracy for arrays can be adversely impacted by propagating background noise, turbulent boundary layer pressure fluctuations on an in-flow array plate, and by de-correlation of the waves propagating from the source of interest through an intervening turbulent shear layer for array measurements from outside of an open jet tunnel. Different 
methods have been developed to improve the dynamic range of measurements for each of these problems $^{6,7}$.

Since pressure fluctuations associated with the turbulent boundary layer over an in-flow or wall mounted array are either uncorrelated over the face of the array, or correlated with convection speeds less than sonic propagation speed, their effects can be minimized by processing methods such as zeroing the diagonal of the cross-spectral matrix, or reduced directly by recessing the array plate behind a porous screen ${ }^{4}$, both approaches were used in this study.

Directional arrays can distinguish desired source levels in the presence of background noise if the levels are higher than the background noise or associated sidelobes in the direction of the desired source. Deconvolutional methods such as DAMAS, CLEAN-SC, TIDY, and others can improve the useful dynamic range by reducing the sidelobe levels of the background sources.

By combining wind-on empty-section background noise signals with the wind-off loudspeaker signals scaled by various gain factors, the minimum source level can be estimated for a range of frequencies, tunnel speeds, source locations, and array processing methods by observing the relative speaker level required for the speaker signature to appear unambiguously in the beamform scan plot. It should be cautioned that this approach yields only approximate estimates for low Mach number flow, and neglects real in-flow source effects such as refraction and scattering through the flow.

Figure 8 shows a composite of the array camera image and the beamformed result at $4 \mathrm{kHz}$ of the superposition of the wind-off loudspeaker signal at the 90 degree location and the empty test section background noise at $100 \mathrm{kts}(51.4 \mathrm{~m} / \mathrm{s})$. The data was processed without background noise subtraction for a tunnel speed of $100 \mathrm{kts}$, which resulted of an apparent 7.5 deg upstream shift of the loudspeaker acoustic source image, since the speaker data was recorded with no flow, but processed with the background noise Mach number of 0.15 . The fan drive noise is evident in the far right of the image. The Kevlar screen was installed on the array fairing for this configuration. The time record length was 40 seconds and TIDY processing was selected. The background noise signal was combined with various levels of speaker signal and then processed to derive an estimate of the minimum speaker source level for reliable detection.

Figure 9 shows 1/3-octave spectra with estimates of source visibility for the Kevlar-treated array at speeds of 50, 75, and $100 \mathrm{kts}$. The peak beamform levels of empty test-section noise (hemispheric scan) are shown as solid blue lines. The dashed green line indicates minimum speaker levels unambiguously observed with only beamforming. The composite cross-spectral matrices were also reprocessed after subtracting background noise cross-spectral matrices from a different data sample as suggested by Blacodon ${ }^{5}$. This method allowed detection of the loudspeaker source levels 5-15 dB lower than possible without the background noise subtraction method, as shown the red lines of in Fig. 9. In Fig. 9a, the speaker was consistently seen with the lowest level considered, and could likely be seen at lower levels, as denoted by the vertical red lines. For this estimate, the background noise data were acquired immediately after the data sample to which the speaker data was added. In a typical wind-tunnel test, empty test-section background noise may be available only during portions of the test entry, typically at the end or beginning. Further assessments of the effectiveness of this and other such methods are anticipated for future tests.

These results should be considered in the context of the limited test time available for measurements, and the small array (size and sensor count) also available for the test. Since this assessment test, a new 48-element, 40 in array pattern using $1 / 4 \mathrm{in}$. condenser microphones from G.R.A.S., Inc. has been assembled, and will be used in upcoming wind tunnel tests in the NFAC 40- by 80- ft wind tunnel. Measurements of empty-section wind tunnel background noise as well as in-flow speaker calibrations are planned for these tests.

\section{Concluding remarks}

During a recent test opportunity in the NFAC 80- by 120- Ft Wind Tunnel, acoustic data was acquired with a 15” D, 24 element phased microphone array (Optinav Array 24Jr), at five speeds from 50 to $100 \mathrm{kts}$ ( 25.7 to $51.4 \mathrm{~m} / \mathrm{s}, \mathrm{M}=0.075$ to 0.15 ) with test section empty except for the array fairing. 
Background noise was measured with the array plate flush with the upper surface of the fairing, as well as recessesed 0.5 in. $(1.27 \mathrm{~cm})$ behind a porous Kevlar screen. Beamform results were obtained with conventional delay-and-sum processing, as well as deconvolutional methods including CLEAN-SC, DAMAS2, and TIDY to assess the locations and levels of the background noise sources. Drive fan noise was prominent for both array configurations at $100 \mathrm{kts}$ below $5 \mathrm{kHz}$. Above this speed, the flush configuration beamform noise was dominated by residual noise from array boundary layer turbulence. With the array plate recessed behind a Kevlar screen, the boundary layer noise is not significant, however noise from turbulence scattering over the upstream junction between the screen and the array frame is significant at $5 \mathrm{kHz}$ and higher. This source can probably be mitigated with local treatment with absorbing foam.

An estimate of minimum broadside source strength for accurate detection by the array was obtained by adding wind-off speaker signals to the empty test-section signals, then assessing the beamform results. The array was able to pick out the speaker source at levels comparable to the strongest background noise levels. Source levels 10-15 dB lower than peak background noise could be distinguished by subtracting cross spectral matrices (CSM) of background-noise only from the composite signal CSM's. This and similar methods will be evaluated during aeroacoustic testing in the NFAC 40- by 80- Ft Wind Tunnel in the near future.

Acknowledgement: This work was supported by the NASA Subsonic Fixed Wing Aerodynamics and Acoustics projects.

\section{References:}

1) "Measurements of 26\%-Scale Airframe Noise in the NASA Ames 40-by80-Ft Wind Tunnel", W. Horne, K. James, T. Arledge, P. Soderman, N. Burnside, S. Jaeger, AIAA-2005-2810, $11^{\text {th }}$ AIAA/CEAS Aeroacoustics Conference, Monterey, CA, May 23-25, 2005.

2) “Array 24 Microphone Phased Array System”, R. Dougherty, http://optinav.com

(The system used in this study was the Array24Jr system, with 18 in. octagonal plate)

3) "Aeroacoustic Characterization of the NASA Ames Experimental Aero-Physics Branch 23- by 48-Inch Subsonic Wind Tunnel with a 24-Element Phased Microphone Array”, B. Costanza, W. Horne, S. Schery, A. Babb, abstracted submitted for AIAA.CEAS $17^{\text {th }}$ Aeroacoustics Conference, June 6-8, 2011

4) "Beamforming/Deconvolustion test - Rev A", R. Dougherty (Optinav) , http://optinav.com, , Jan 10, 2011

5) “Jet Noise Beamforming with Several Techniques", R. Dougherty (Optinav), Berlin Beamforming Conference, Feb 24-25, 1010

6) "Concepts for Reducing the Self-Noise of In-Flow Acoustic Sensors and Arrays", W. Horne and K. James, AIAA-1999-1815, AIAA/CEAS $5^{\text {th }}$ Aeroacoustics Conference, Bellevue, WA, May 10-12, 1999

5) “Array Processsing for Noisy Data: Application for Open and Closed Wind Tunnels”, D. Blacodon, AIAA Journal, 2011, vol 49, no. 1, pp 55-66. 


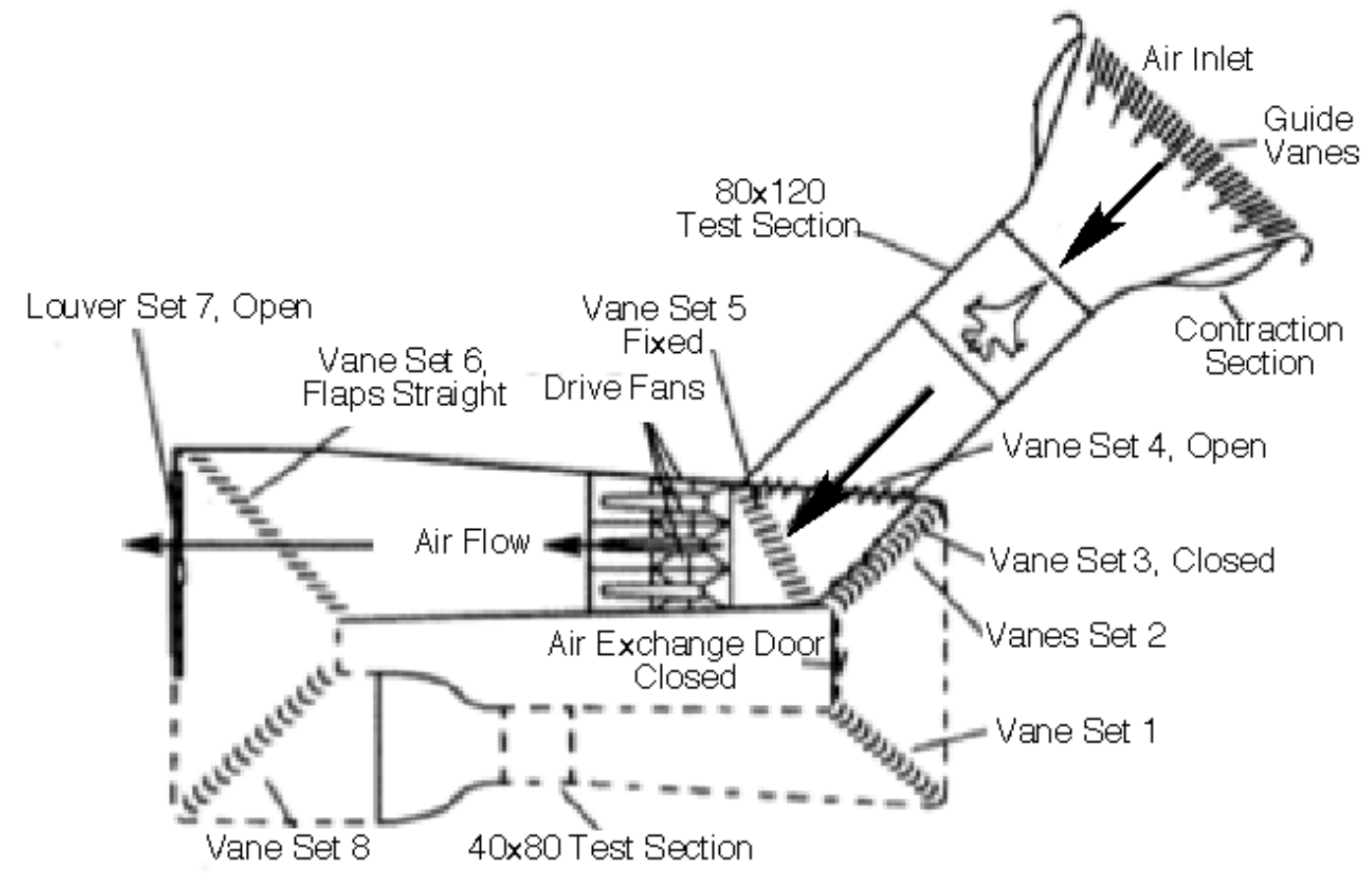

Figure 1. NFAC 80-by120-Ft Wind Tunnel layout. The test section has a 6” deep acoustic liner consisting of bulk fiberglas covered by perforated sheet. $80 \times 120-\mathrm{Ft}$ ( $24.4 \times 36.6 \mathrm{~m}$ ) test section speed maximum is $51.4 \mathrm{~m} / \mathrm{s}(100 \mathrm{kt})$, or $\mathrm{M}=0.15$. 

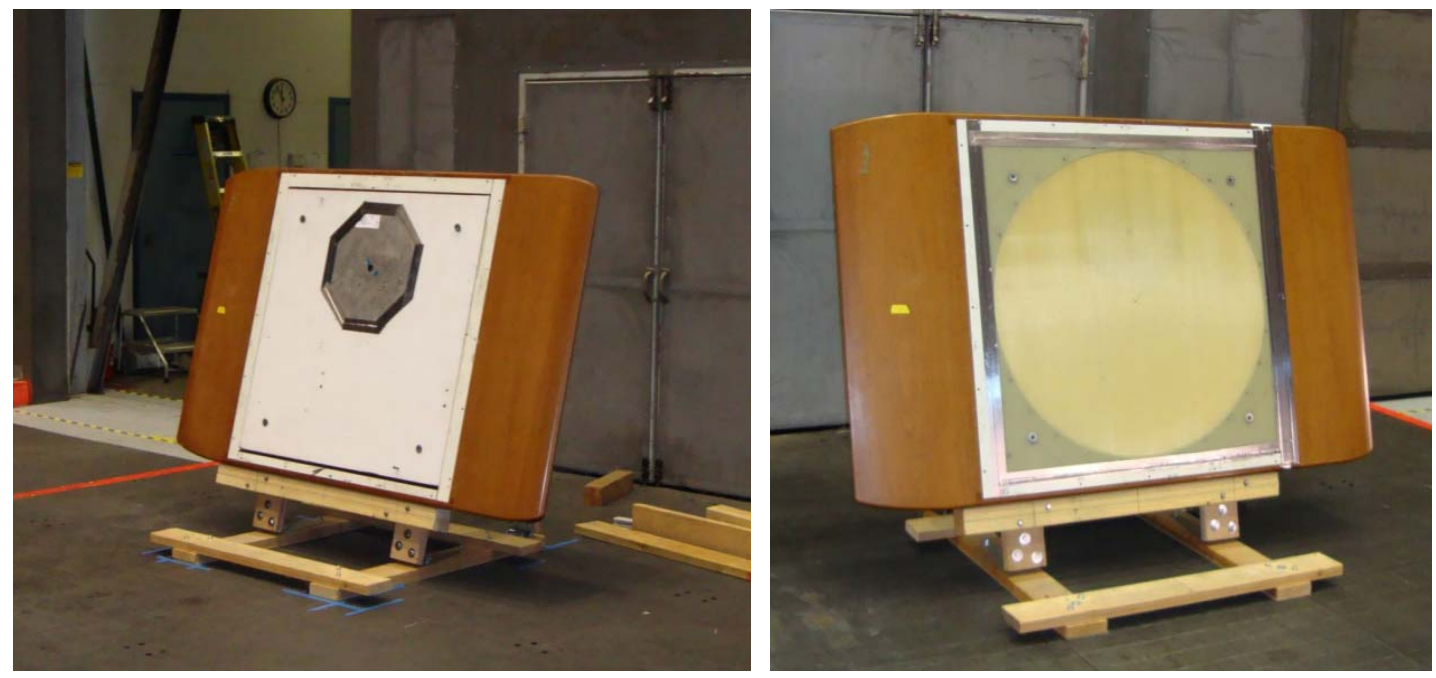

Figure 2. (left) 24-element 15 in. diameter microphone array mounted flush to surface of array fairing. (right) Array plate recessed $1 / 2$ in. $(1.27 \mathrm{~cm})$ behind porous Kevlar screen

24 element $f: 1000 \mathrm{~Hz}$ : source at $x, y, z=0,0,240$ $3 \mathrm{~dB}$ point: $\mathrm{NaN}$

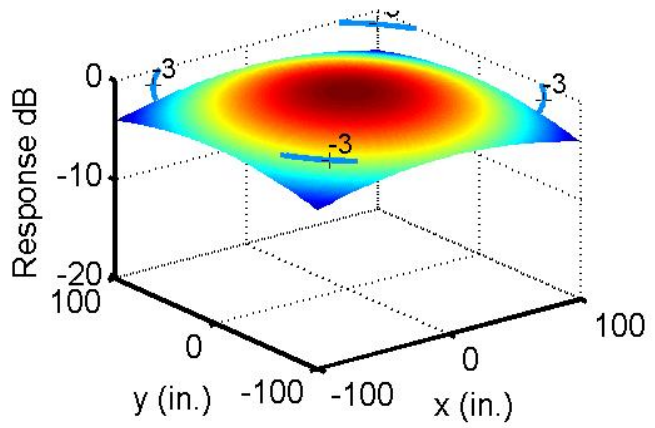

24 element $f: 10000 \mathrm{~Hz}$ : source at $x, y, z=0,0,240$ $3 \mathrm{~dB}$ point:10.67

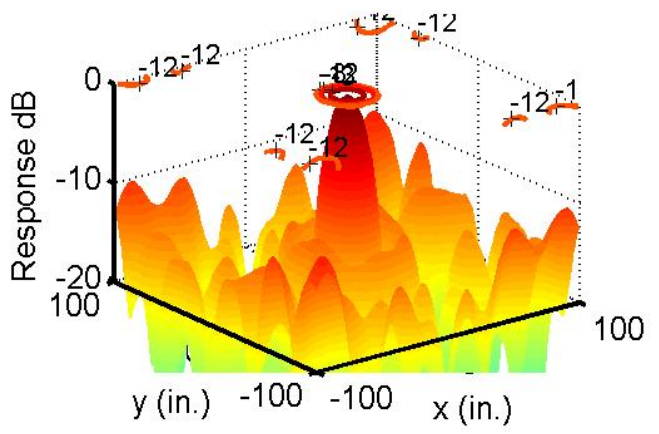

24 element $f: 2500 \mathrm{~Hz}$ : source at $x, y, z=0,0,240$ $3 \mathrm{~dB}$ point: 43.52

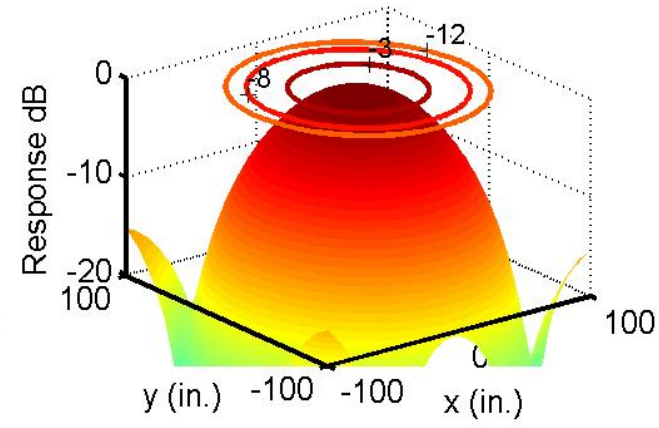

24 element $f: 15000 \mathrm{~Hz}$ : source at $x, y, z=0,0,240$ $3 \mathrm{~dB}$ point: 7.06

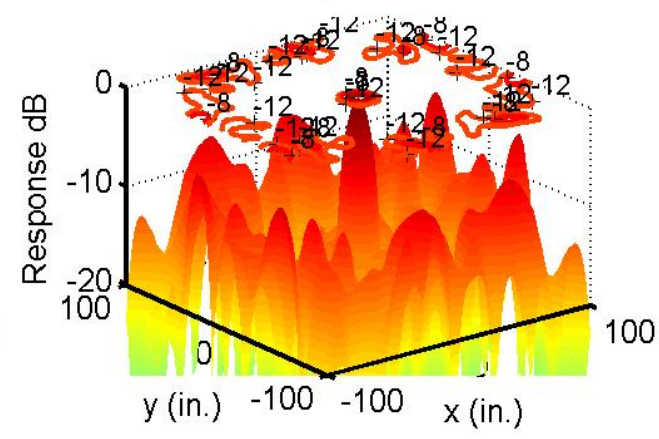

Fig. 3. Response of 24 element array to point source on axis $240 \mathrm{in.}(6.1 \mathrm{~m})$ at 1, 2.5, 10, and $15 \mathrm{kHz}$ with conventional beamforming 


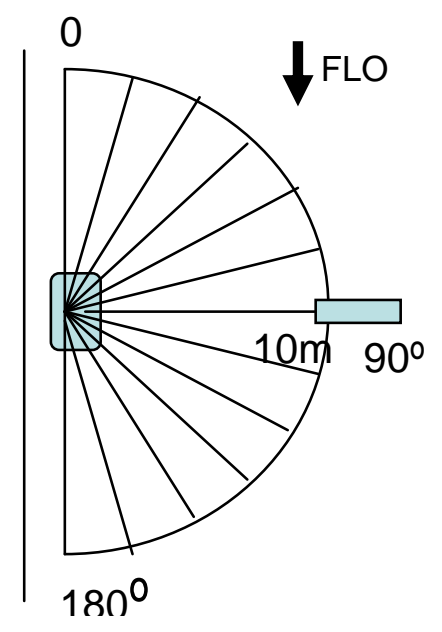

Fig. 4 Microphone array fairing and speaker locations in test section of NFAC 80-by120 ft wind tunnel. A
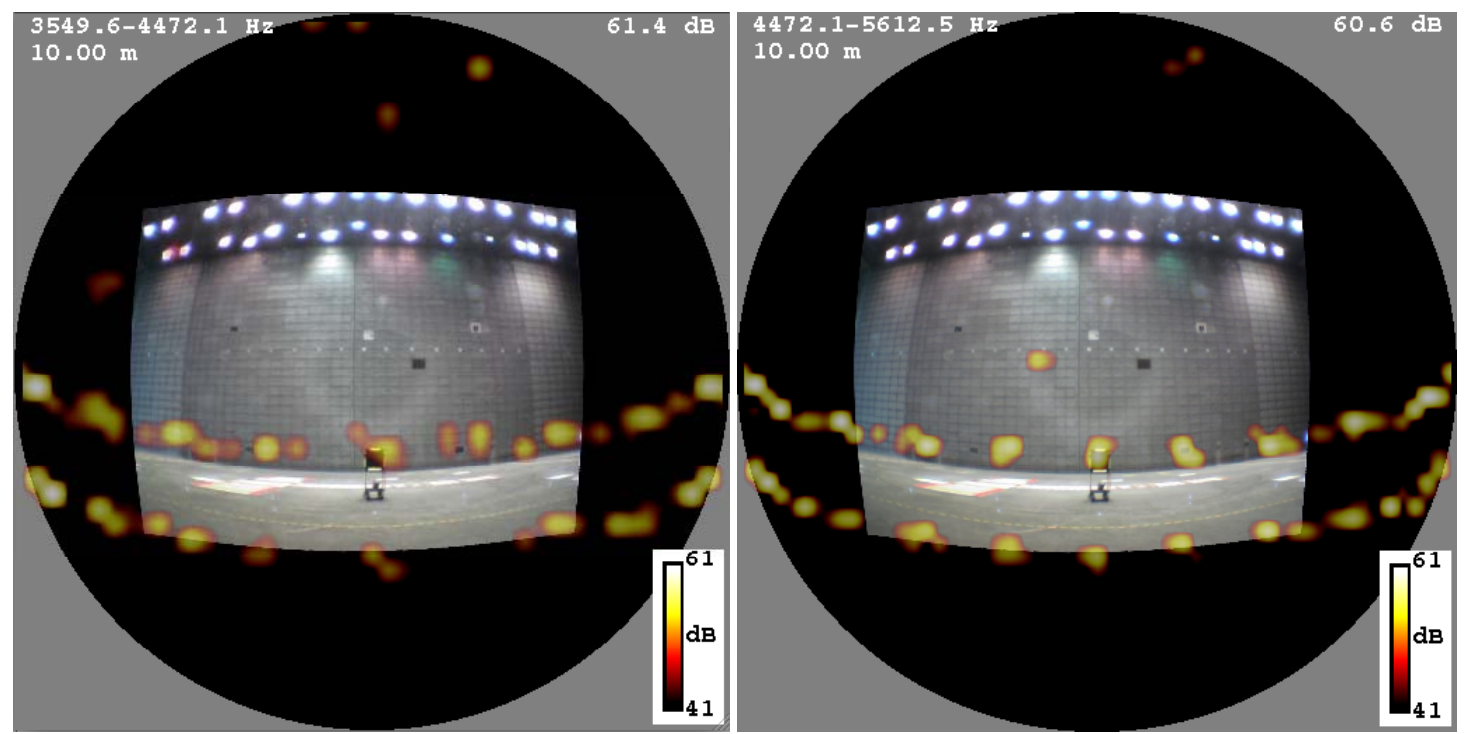

Figure 5. Beamform result of superposition of single loudspeaker $\mathrm{M}=0$, at 13 locations: $0^{\circ}, 15^{\circ}, \ldots 180^{\circ}$ using Optinav ImageJ software with enhanced TIDY algorithm, Left figure $3980 \mathrm{~Hz}$ band, right figure: $5000 \mathrm{~Hz}$ band. hemispherical display. Note grazing incidence reflections of speaker signals from acoustically treated tunnel floor 


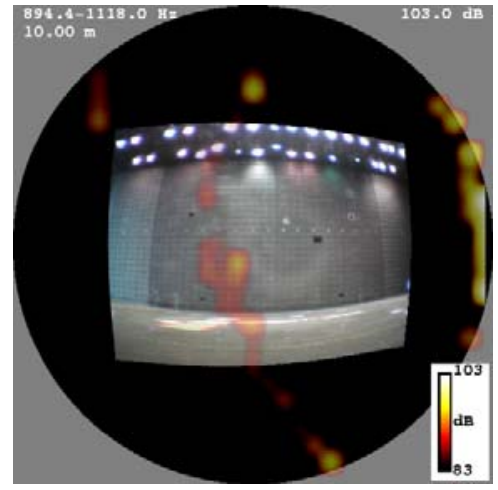

a) Flush, 1 kHz, pk $103 \mathrm{~dB}$

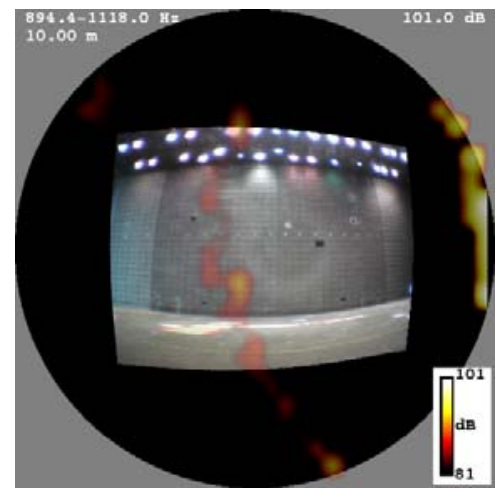

d) Kevlar, 1kHz, pk 101dB

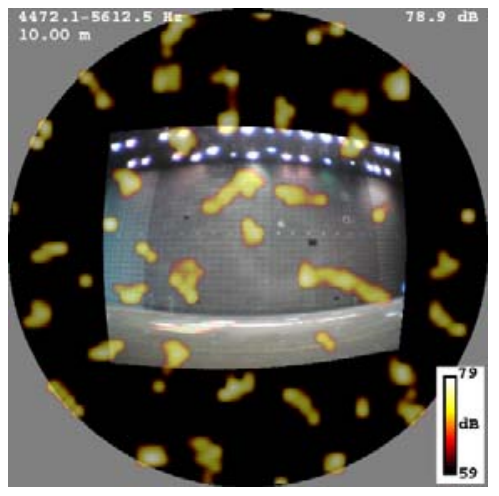

b) Flush, $5 \mathrm{kHz}$, pk $79 \mathrm{~dB}$

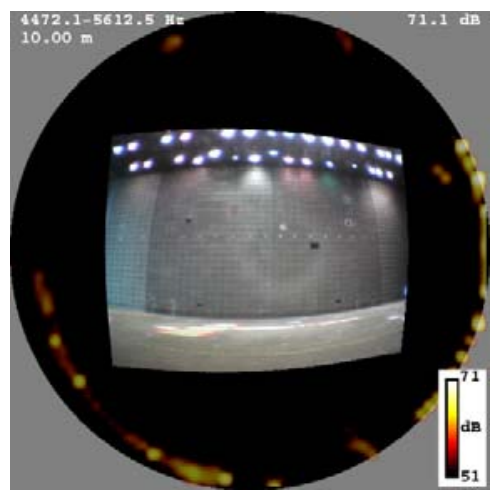

e) Kevlar, 5 kHz $71 \mathrm{~dB}$
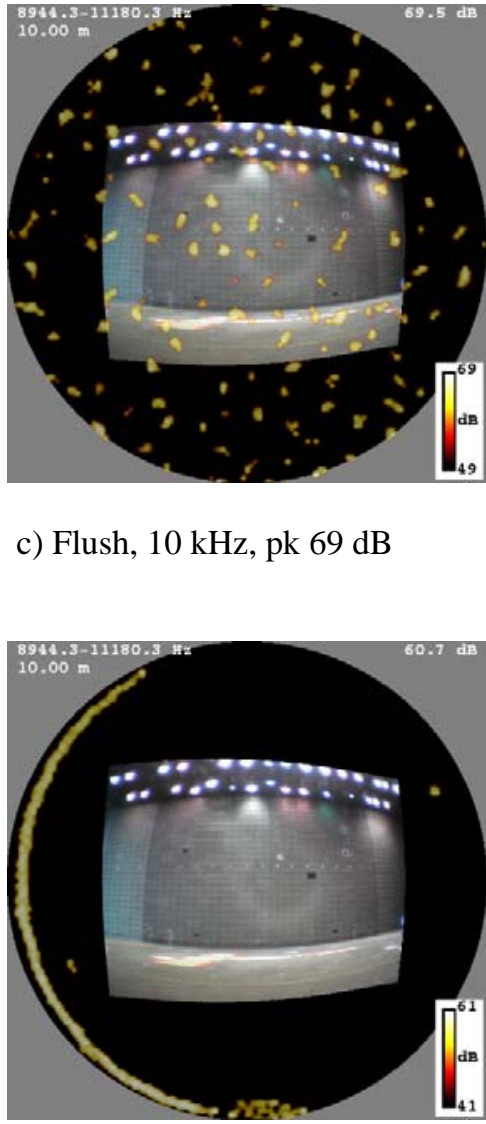

c) Flush, 10 kHz, pk $69 \mathrm{~dB}$

f) Kevlar, $10 \mathrm{kHz}$, pk $61 \mathrm{~dB}$

Fig. 6. Hemispherical beamform plots using Optinav Tidy-enhanced algorithm, empty test section at $\mathrm{M}=$ $0.15(\mathrm{~V}=51.4 \mathrm{~m} / \mathrm{s})$, flow from left to right. Upper row (a-c), flush array plate at 1, 5, and $10 \mathrm{kHz}$. Lower row (d-f), array plate recessed 0.5 in $(1.27 \mathrm{~cm}$ ) behind porous Kevlar screen. Note drive noise (and sidelobe) to right of a) and d), flow noise in flush configuration in b) and c), and scattering of turbulence at leading edge of Kevlar aperture (left) in e) and f) 

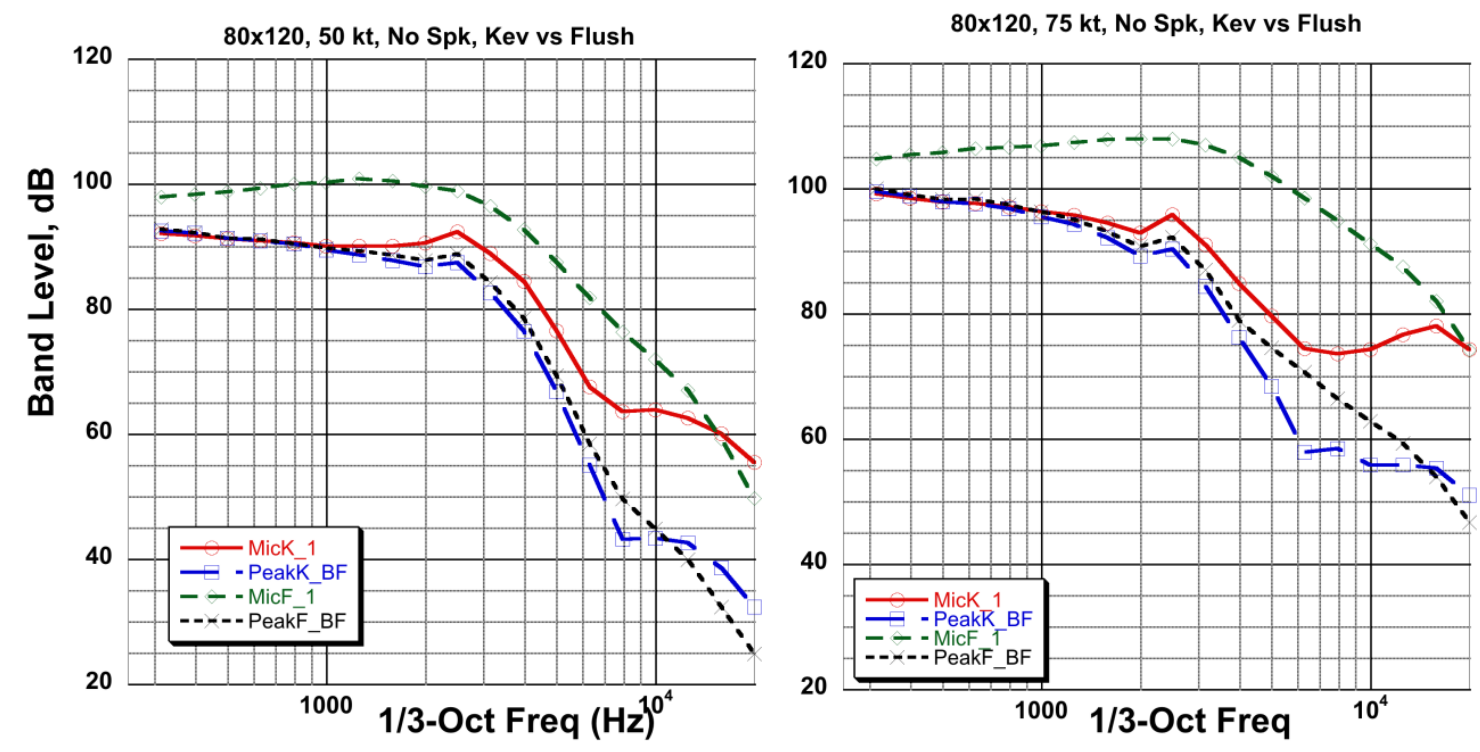
a) $\mathrm{M}=0.075, \mathrm{~V}=17.1 \mathrm{~m} / \mathrm{s}=50 \mathrm{kts}$
b) $\mathrm{M}=0.115, \mathrm{~V}=34.3 \mathrm{~m} / \mathrm{s}=75 \mathrm{kts}$

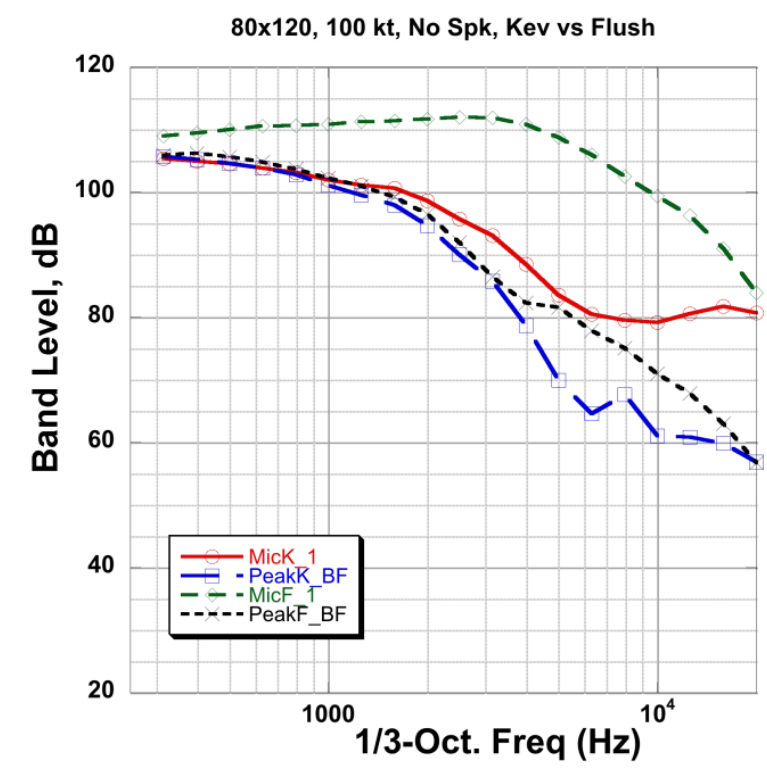

c) $\mathrm{M}=0.15, \mathrm{~V}=51.4 \mathrm{~m} / \mathrm{s}=100 \mathrm{kts}$

Figure 7. (a,b,c) Background noise spectra for central microphone (\#1) and peak beamform levels, flush and Kevlar configurations at $\mathrm{M}=0.05,0.1$, and 0.15 . 


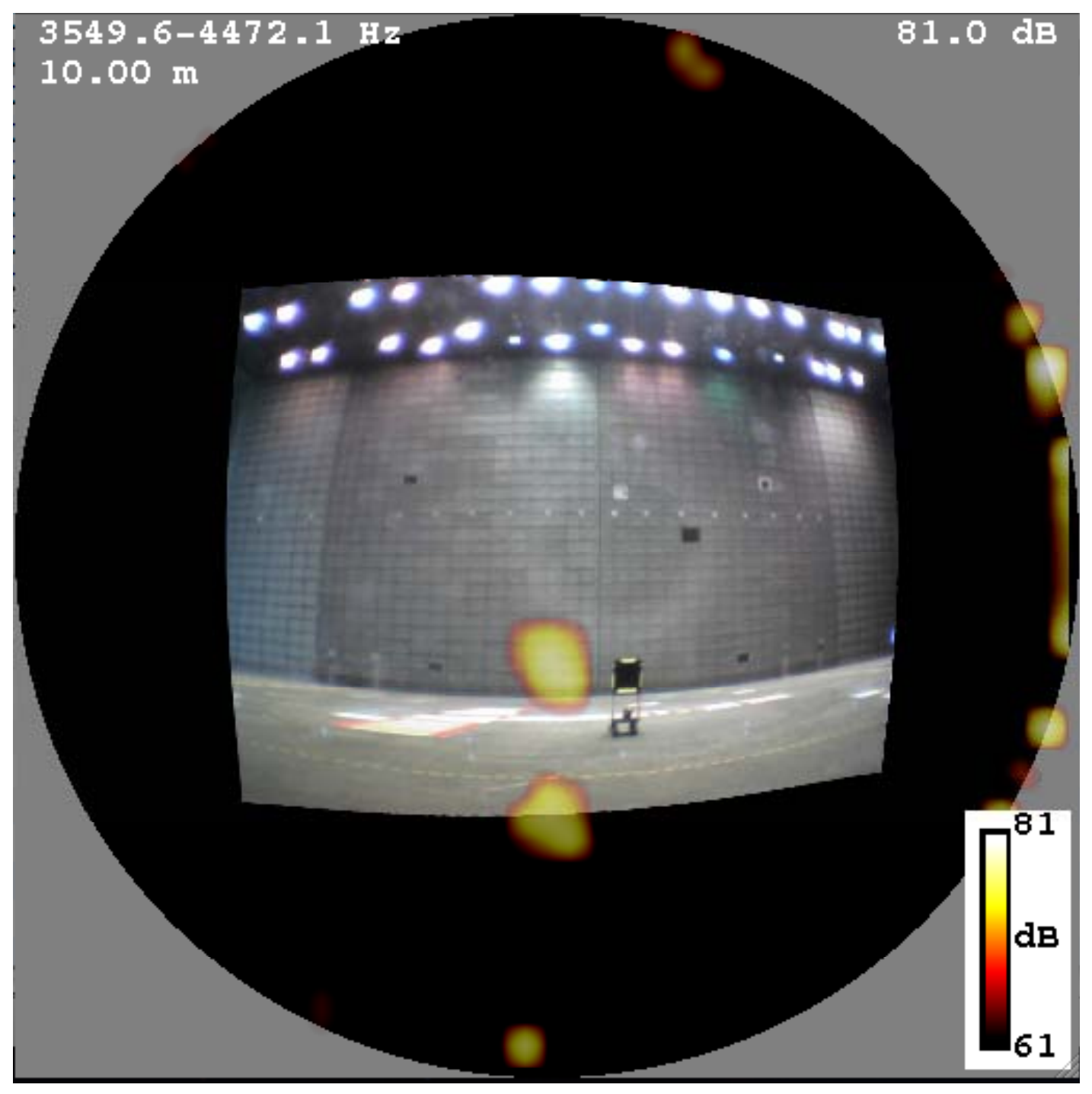

Figure 8. Beamform result of superposition of signal from $90^{\circ}$ speaker, wind-off, and tunnel background noise, $\mathrm{M}=0.15$ (100kts), processed for $\mathrm{M}=0.15$. 


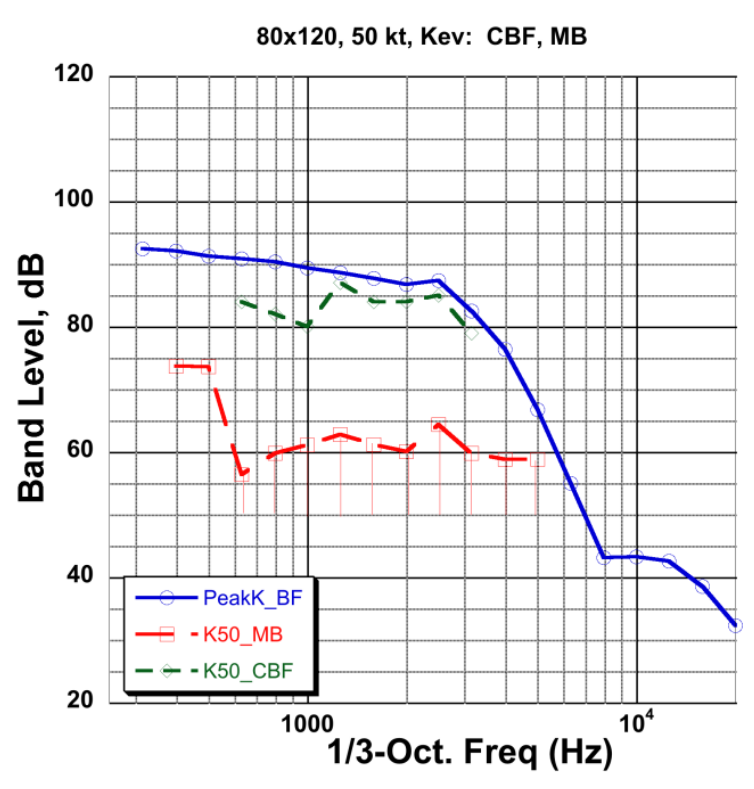

a) $V=50 \mathrm{kts}$

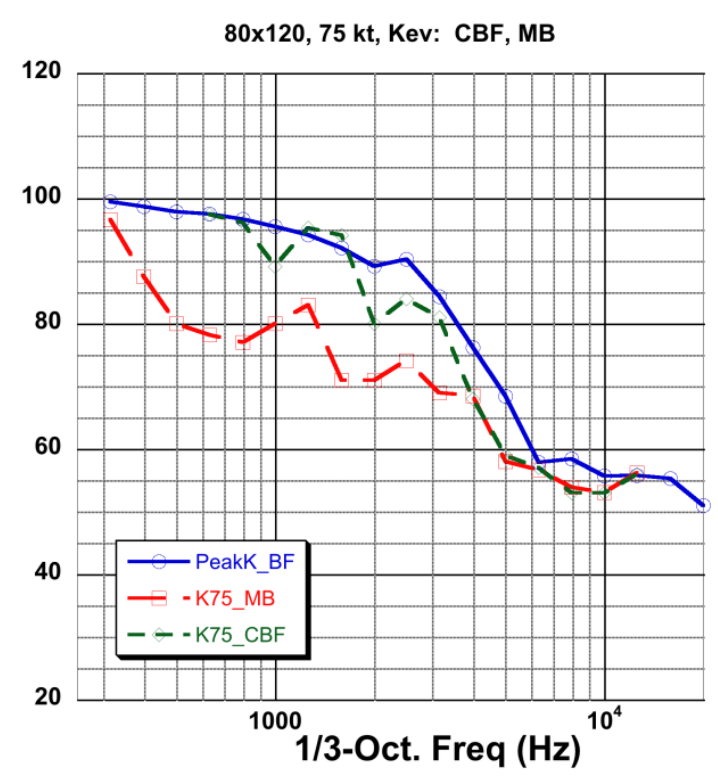

b) $\mathrm{V}=75 \mathrm{kt}$

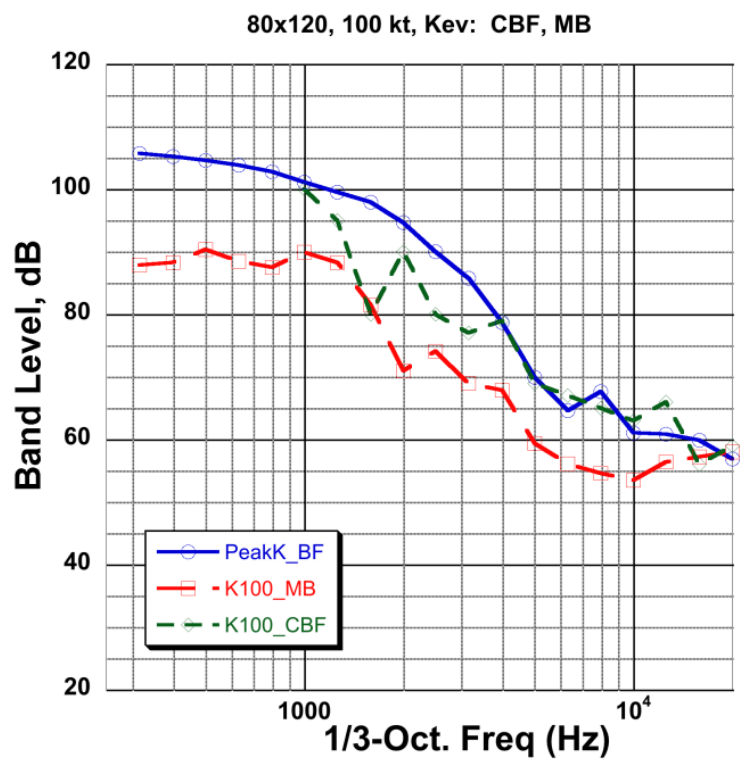

c) $\mathrm{V}=100 \mathrm{kt}$

Figure $9(\mathrm{a}, \mathrm{b}, \mathrm{c})$. 1/3 octave band plots of stimated visibility of broadside source from composite of background noise and wind-off speaker with variable gain, cross-spectral-matrix (CSM) of background noise from different acquisition bacground-only CSM. Tunnel speed $=50,75$, and $100 \mathrm{kt}$. The blue solid lines are the peak beamformed levels of empty tunnel background noise. The green dotted lines denote minimum levels of sources observable with conventional beamforming (CBF). The red dashed curve indicates levels for which sources were observed after subtracting background noise CSM from a different test point from composite signal before processing with CBF. 